\title{
BIOLOGICAL PROPERTIES OF A NEW THIAMINE DERIVATIVE, CYCLOCARBOTHIAMINE ${ }^{1}$
}

\author{
YUICHI SHIOBARA, NOBORU SATO, HIROSHIGE HOMMA, \\ REIKO HATTORI, AND MASUO MURAKAMI ${ }^{2}$ \\ Central Research Laboratory, Yamanouchi Pharmaceutical \\ Company, Azusawa-cho, Itabashi-ku, Tokyo
}

(Received November 5, 1966)

In recent years, intensive efforts have been made for the synthesis of thiamine derivatives having biological advantages over thiamine (1). The derivatives developed so far are characterized by easier absorption from the intestine and quantitative regeneration of thiamine following absorption. As a result, their administration results in the accumulation of thiamine in the blood and tissues in such a high concentration as is unattainable with thiamine itself.

In the course of our study intended to develop a still better thiamine compound, it was found that one of the new derivatives, which was obtained by the reaction of thiamine with phosgene and for which we propose the name cyclocarbothiamine $^{3}(2)$, is an excellent substitute for thiamine with regard to the above properties.

This paper deals with the general biological characteristics of this compound.<smiles>CC(=C1CCOC(=O)S1)N(C=O)Cc1cnc(C)nc1N</smiles>

Cyclocarbothiamine

\section{EXPERIMENTAL}

\section{Thiamine Activity in vivo}

Rats-Male Wistar strain rats, 4 weeks old, were maintained on a thiaminefree diet and rendered thiamine-deficient in the same manner as described previously (3). When the animals were sufficiently depleted of thiamine as revealed by the cessation of growth, three graded doses of thiamine $(5,10$ and $20 \mu \mathrm{g})$ or equimolar amounts of cyclocarbothiamine dissolved in $0.2 \mathrm{ml}$ of water were administered daily by a stomach tube and their effects on body weight increase were

\footnotetext{
${ }^{1}$ Studies on Cyclocarbothiamine. II.

2 塩原有一, 佐藤 登, 本間弘茂, 服部礼子, 村上增雄.

3 The name cycotiamine has provisionally been proposed for this compound by WHO as its International Nonproprietary Name (1966. 9.6).
} 
compared. The control animals received the same volume of water instead.

Rice-birds Male rice-birds (Uroloncha striata var. domestica), weighing approximately $13 \mathrm{~g}$, were maintained on a thiamine-deficient diet, the composition of which had previously been presented (2). The birds received daily $3 \mu \mathrm{g}$ of thiamine or an equimolar amount of cyclocarbothiamine dissolved in $0.05 \mathrm{ml}$ of water and their body weights were checked every three days. The control birds were given the same volume of water and observation was made over a period of 20 days.

\section{Intestinal Absorption and Deposition in Tissues}

Total Thiamine Contents in Rabbit Blood Following Oral Administration of Thiamine and Cyclocarbothiamine - Male rabbits, weighing approximately $2.5 \mathrm{~kg}$, were used after being fasted for 24 hours. Thiamine and cyclocarbothiamine were administered orally as an aqueous solution at three different dose levels equivalent to 5,10 and $20 \mathrm{mg}$ of thiamine per $\mathrm{kg}$ of body weight, respectively. At appropriate time intervals, blood samples were taken by cardiac puncture and total thiamine contents were determined by the method of Fujiwara et al. $(4,5)$. Cocarboxylase was also assayed manometrically according to Uehara et al. (6).

Total Thiamine Contents in the Liver and Kidney of Rats Following Oral Administration of Thiamine and Cyclocarbothiamine - Male Wistar strain rats, ranging in body weight from 130 to $150 \mathrm{~g}$, were dosed orally with thiamine, $1 \mathrm{mg}$, or an equimolar amount of cyclocarbothiamine. One or five hours after the dosage, the animals were killed by decapitation and the total thiamine contents in the liver and kidney were measured.

Urinary Excretion of Thiamine Following Oral Administration of Thiamine and Cyclocarbothiamine to Human Subjects - The two compounds were given orally as an aqueous solution of $50 \mathrm{ml}$ to healthy male subjects, about 25 years of age, in an amount equivalent to 10,25 and $50 \mathrm{mg}$ of thiamine, respectively. Sixhour urine was collected under the addition of acetc acid and assayed for thiamine contents.

3. Thiamine Levels in the Blood and Urine Following Intravenous Administration of Thiamine and Cyclocarbothiamine to Rabbits

Thiamine or cyclocarbothiamine dissolved in $1.0 \mathrm{ml}$ of physiological saline was injected into a marginal ear vein of male rabbits, about $2.5 \mathrm{~kg}$, in a dose equivalent to $5 \mathrm{mg}$ of thiamine per $\mathrm{kg}$ body weight. At the times indicated, blood samples were withdrawn as described before and assayed for total thiamine contents.

Urine was collected at the same intervals by the use of a catheter and analysed similarly after appropriate dilution with distilled water.

\section{Action of Thiaminases on Cyclocarbothiamine}

Enzyme preparations of thiaminase I and II were the same as described previously (7).

Thiaminase I The reaction mixture contained the following components in a final volume of $10 \mathrm{ml}: 4 \mu \mathrm{g}$ substrate, $133 \mu$ moles phosphate buffer, $\mathrm{pH} 6.0,10$ $\mu$ moles aniline and $2 \mathrm{ml}$ of 20 -fold diluted culture supernatant of Bacillus thiaminolyticus Matsukawa et Misawa.

The mixture was incubated at $37^{\circ}$. At the indicated time intervals, an aliquot 
of $1.0 \mathrm{ml}$ was removed and added to $1.0 \mathrm{ml}$ of $0.1 \mathrm{~N} \mathrm{NaOH}$, which was allowed to stand at room temperature for 10 minutes. During this treatment, cyclocarbothiamine was quantitatively converted to thiamine. Three $\mathrm{ml}$ of $25 \% \mathrm{KCl}$ in $0.1 \mathrm{~N} \mathrm{HCl}$ was then added and thiamine was measured by the thiochrome method (4). When thiamine was used as the substrate, the alkaline treatment was omitted.

Thiaminase II - The composition of the reaction mixture in $10 \mathrm{ml}$ was as follows : $4 \mu \mathrm{g}$ substrate, $133 \mu$ moles phosphate buffer, $\mathrm{pH} 7.0$, and $2 \mathrm{ml}$ of 10 -fold diluted culture supernatant of Bacillus aneurinolyticus Kimura et Aoyama.

Subsequent procedure was the same as described above for thiaminase I.

\section{RESULTS}

\section{Thiamine Activity in Rats and Rice-birds}

As is shown in Fig. 1, thiamine activity of cyclocarbothiamine was in no way different from that of thiamine, as judged by the growth-promoting effect on thiamine-deficient rats. Similarly, the two compounds prevented the development of thiamine-deficiency in rice-birds equally well (Fig. 2).

These facts indicate that cyclocarbothiamine is completely transformed into thiamine in the body, which will be demonstrated in full detail in the following paper.

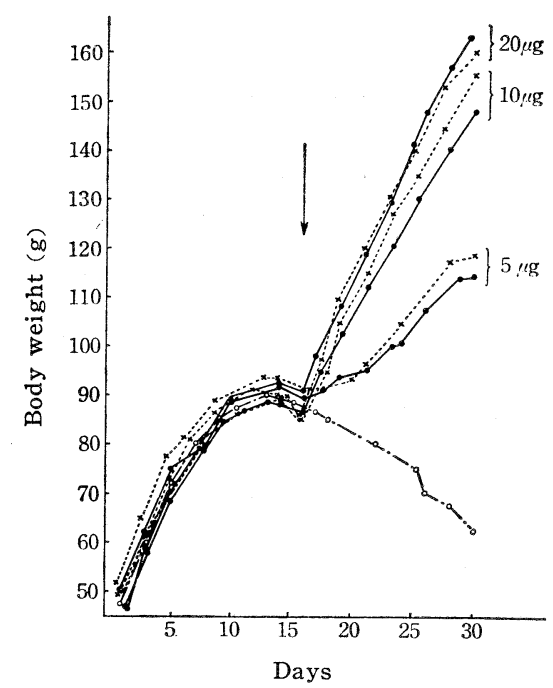

FIG. 1 Growth-promoting Effect of Thiamine and Cyclocarbothiamine on Thiaminedeficient Rats

Each curve represents the average of eight animals. The arrow indicates the onset of administration.

Dose : 5,10 and $20 \mu \mathrm{g}$ equivalent of thiamine per day. $\bullet$, cyclocarbothiamine; $\times$, thiamine; O, control.

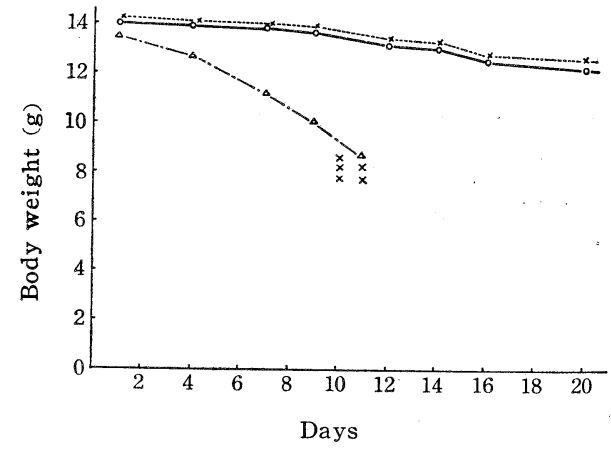

FIG. 2 Preventive Effect of Thiamine and Cyclocarbothiamine on the Thiamine-deficiency of Rice-birds

Each curve is the average of five birds. The $\operatorname{cross}(x)$ indicates death.

Dose : $3 \mu \mathrm{g}$ equivalent of thiamine per day. $\bigcirc$, cyclocarbothiamine; $\times$, thiamine; $\Delta$, control. 


\section{Intestinal Absorption and Deposition in Tissues of Cyclocarbothiamine}

Total thiamine contents in the blood after oral administration of cyclocarbothiamine increased remarkably in proportion to the dosage, which presents a striking contrast to the corresponding effect of thiamine (Fig. 3). The same was true

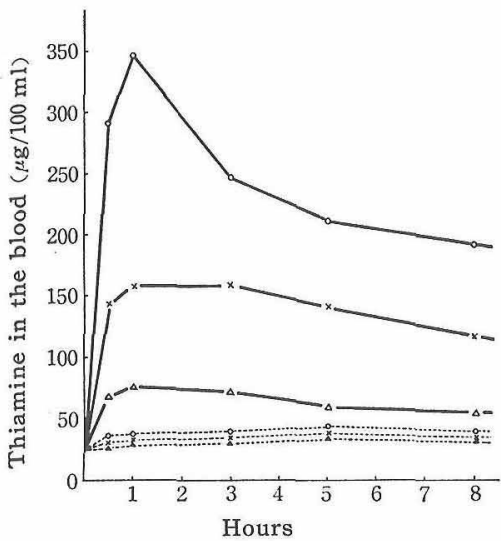

FIG. 3 Total. Thiamine Contents in the Blood Following Oral Administration of Thiamine and Cyclocarbothiamine to Rabbits

Each curve is the average of seven animals. Dose : $5(\Delta), 10(x)$ and $20(0) \mathrm{mg}$ equivalent of thiamine per $\mathrm{kg}$ body weight. -, cyclocarbothiamine; ..., thiamine.

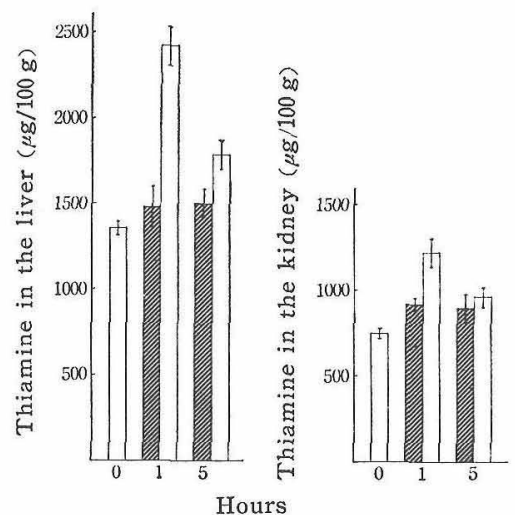

FIG. 5 Total Thiamine Contents in the Liver and Kidney Following Oral Administration of Thiamine and Cyclocarbothiamine to Rats

Each value is the average of five animals and the vertical line indicates the standard deviation of the mean.

Dose: $1 \mathrm{mg}$ equivalent of thiamine per animal. $\square$, cyclocarbothiamine; $\square$, thiamine.

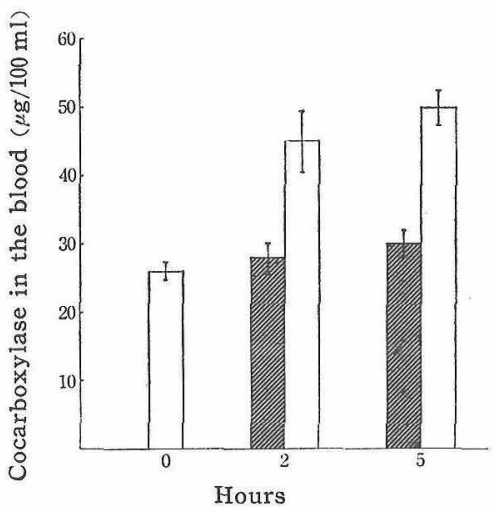

FIG. 4 Cocarboxylase Levels in the Blood Following Oral Administration of Thiamine and Cyclocarbothiamine to Rabbits

Each value is the average of seven animals and the vertical line represents the standard deviation of the mean.

Dose: $10 \mathrm{mg}$ equivalent of thiamine per $\mathrm{kg}$ body weight.

[], cyclocarbothiamine; 갈, thiamine.

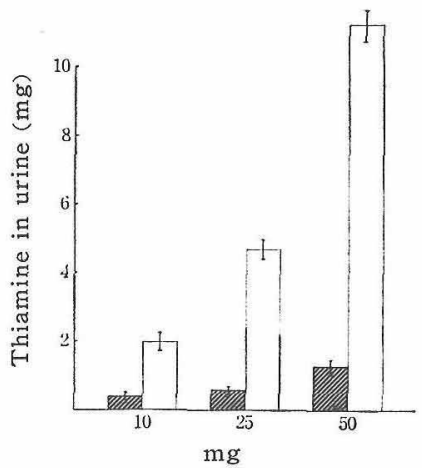

FIG. 6 Urinary Excretion of Thiamine Following Oral Administration of Thiamine and Cyclocarbothiamine to Human Subjects Each value is the average of five subjects and the vertical line represents the standard deviation of the mean. Determination was done on six-hour urine.

Dose: 10, 25 and $50 \mathrm{mg}$ equivalent of thiamine per subject.

[, cyclocarbothiamine; [1: thiamine. 
of blood cocarboxylase and total thiamine levels in the liver and kidney (Figs. 4,5).

These data suggest that the intestinal absorption of cyclocarbothiamine proceeds in large quantities, whereas that of thiamine is severely restricted. A considerable amount of thiamine detected in urine after oral dosage also supports this view (Fig. 6).

As will be shown later, cyclocarbothiamine is rapidly converted into thiamine after absorption and not a trace of the compound is detected unaltered in blood sample taken 30 minutes after oral dosage. Therefore, the total thiamine measured here does not include cyclocarbothiamine itself.

3. Retention of Thiamine in the Body Following Intravenous Administration of Cyclocarbothiamine

Rabbits, when loaded with thiamine intravenously, excreted a fairly large portion of it into urine in a comparatively short period. In the case of cyclocarbothiamine, its urinary output tended to be delayed (Fig. 7).

This, taken together with the time course of total thiamine levels in the blood (Fig. 8), proves that cyclocarbothiamine is retained in the body for a longer period presumably because of its stronger affinity for the blood and tissues.

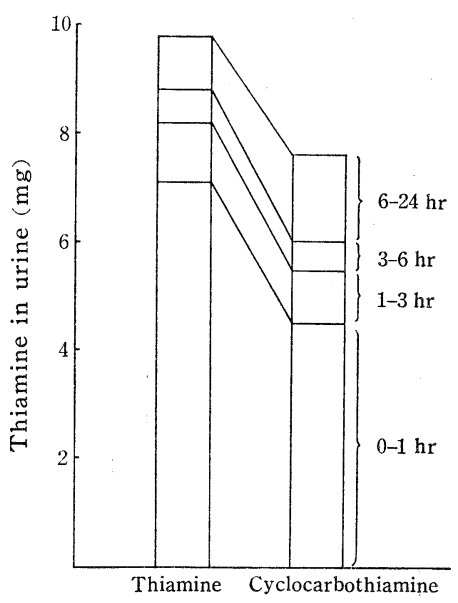

FIG. 7 Urinary Excretion of Thiamine Following Intravenous Administration of Thiamine and Cyclocarbothiamine to Rabbits

Each value is the average of six animals. Dose: $5 \mathrm{mg}$ equivalent of thiamine per $\mathrm{kg}$ body weight.

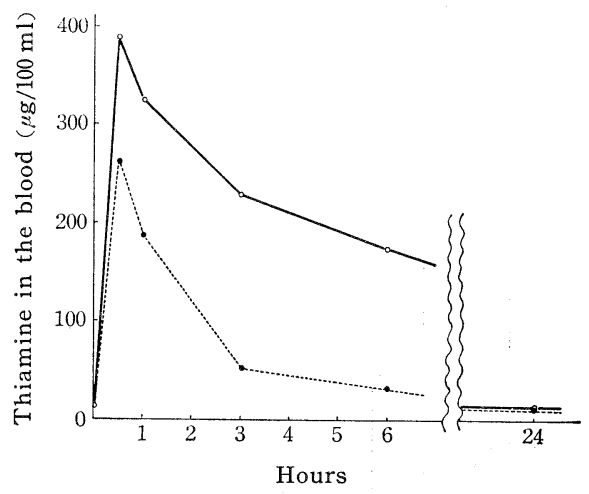

FIG. 8 Total Thiamine Contents in the Blood Following Intravenous Administration of Thiamine and Cyclocarbothiamine to Rabbits

Each curve is the average of three animals. Dose: $5 \mathrm{mg}$ equivalent of thiamine per $\mathrm{kg}$ body weight.

, cyclocarbothiamine; $\bullet$ thiamine.

\section{Stabiliy of Cyclocarbothiamine to Thiaminases}

As is evident in Fig. 9, cyclocarbothiamine survived the action of both types of thiaminase perfectly, while under identical conditions, about $80 \%$ of thiamine was decomposed. 
Thiaminase I

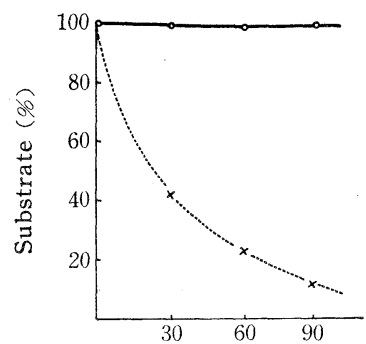

Thiaminase II

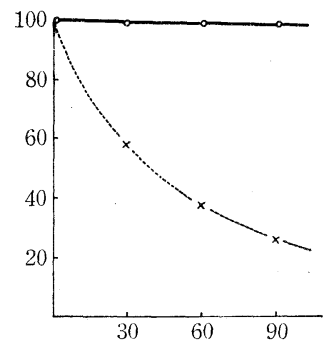

$\min$

FIG. 9. Action of Thiaminase on Thiamine and Cyclocarbothiamine $\times$, thiamine; $O$, cyclocarbothiamine.

Experimental conditions are given in the text.

\section{DISCUSSION}

It has been repeatedly demonstrated that the intestinal absorption of thiamine proceeds only to a limited extent and its oral administration in a large dose results in the excretion of its major part in feces. Therefore, efficient deposition of thiamine in the tissues through oral route cannot be effected with thiamine itself.

Allithiamine is a typical example which has overcome this difficulty by modifying the chemical structure of thiamine $(8,9)$. Several similar compounds have been developed so far and their biological advantages may be summarized as follows.

(a) Oral administration brings about far higher thiamine levels in the blood as well as in the tissues.

(b) Parenteral administration effects better accumulation of thiamine in various parts of the body.

(c) These modified thiamines are not destroyed by thiaminases produced by certain types of intestinal bacteria.

As is seen from the experimental findings presented in this paper, cyclocarbothiamine may be regarded as a new compound which satisfies the above requirements. Furthermore, the following feature can be pointed out as an additional advantage of this compound.

In the process of its enzymatic transformation into thiamine, cyclocarbothiamine splits off its carbonyl segment which is imparted by phosgene as carbon dioxide, no unphysiological substances being produced. This is definitely a desirable property in view of the fact that this class of compounds have come to be used in increasingly large doses for clinical purposes.

Pharmacological aspects of this compound will be reported separately.

\section{SUMMARY}

Cyclocarbothiamine, a new thiamine derivative obtained by the reaction of thiamine with phosgene, was found to have a number of advantages over thiamine in its biological properties. 
1. Its thiamine activity was indistinguishable from that of thiamine when examined in vivo with rats and rice-birds.

2. Oral administration of cyclocarbothiamine resulted in far higher thiamine contents in the rabbit blood as well as in the liver and kidney of rats. Marked increase was observed also in blood cocarboxylase levels of rabbits.

These data indicate that, as against thiamine, cyclocarbothiamine is absorbed from the intestine in large quantities.

3. Intravenously injected cyclocarbothiamine similarly brought about higher blood thiamine levels in rabbits than did thiamine and its urinary excretion was delayed.

4. Unlike thiamine, cyclocarbothiamine was not decomposed by either thiaminase I of Bacillus thiaminolyticus or thiaminase II of Bacillus aneurinolyticus.

\section{REFERENCES}

1. Kawasaki, C., Vitamins and Hormones, 21, 69 (1963) Academic Press, New York.

2. Murakami, M., M., Takahashi, K., Hirata, Y., and Iwamoto, M., J. Vitaminol., 13, (1967).

3. Shiobara, Y., Sato, N., Homma, H., Hattori, R., Yogi, K., and Murakami, M., J. Vitaminol., 11, 302 (1965).

4. Fujiwara, M., and Matsui, K., Anal. Chem. 25, 810 (1953).

5. Fujiwara, M., Vitamins, 9, 148 (1955).

6. Uehara, K., and Muramatsu, I., Vitamins, 11, 583 (1956).

7. Shiobara, Y., Sato, N., Hattori, R., Yogi, K., and Murakami, M., J. Vitaminol., 11, 308 (1965).

8. Fujiwara, M., Nanjo, H., Arai, T., and Suzuoki, Z., J. Biochem., 41, 273 (1954).

9. Matsukawa, T., and Yurugi, S., Proc. Japan Acad., 28, 146 (1952). 